\title{
When the Mind Affects the Heart
}

\author{
Cláudio Garcia Capitão \\ Universidade São Francisco, São Paulo, Brazi \\ Email: cgcapitao@uol.com.br
}

Received 12 November 2015; accepted 26 December 2015; published 29 December 2015

Copyright (C) 2015 by author and Scientific Research Publishing Inc.

This work is licensed under the Creative Commons Attribution International License (CC BY).

http://creativecommons.org/licenses/by/4.0/

c) (i) Open Access

\begin{abstract}
This article aims to theoretically discuss the relationship between psychosomatic symptoms and heart diseases. It was used, as research technique, the narrative literature review, unsystematic, which consisted in presenting an open theme. Many authors point out the influence of the mind over the body-especially through emotions, psychic conflicts, stress-as responsible for, or adjuvants in the etiopathogenesis of many diseases. Emotions are acute emotional reactions triggered by external or internal stimuli, usually accompanied by neurodegenerative, visceral, hormonal and vascular somatic reactions. The conclusion is that heart diseases are multidetermined, influenced by environmental, organic and psychodynamic conditions.
\end{abstract}

\section{Keywords}

Psychosomatics, Theoretical Study, Heart Diseases

\section{Introduction}

The heart has a universal symbolic representation as the seat of emotions, life and also death. When an individual is affected by a disease, emerge feelings such as fear, anxiety, and uncertainty, among others. But when it comes to heart disease, it seems that such feelings are exacerbated, as if something valuable that the person has is injured and about to be destroyed (Tamagnini, 2014; Ismael \& Oliveira, 2001).

Currently the society has exerted a great pressure in relation to have an athletic body, with sculptural forms for the physical well-being. Thus, a healthy eating combined with exercise is increasingly sought, all in favor of the "dictatorship" of the perfect body. However, beyond the body care, one should also be equally careful about the mental health in order to get a comprehensive quality of life. That is to say, therefore, that they do not realize the signs and symptoms which the body emits until suffering a limitation. Usually, suffering is the means by which people remember that they "have a body" (Bonomo \& Araujo, 2009; Botega, 2002).

From Freud's studies on hysteria, there was further development in research on the interrelationship between psyche and soma, which provided the birth and growth of psychosomatic schools such as the School of Chicago, founded by Franz Alexander, and the School of Paris, founded by P. Marty. Although the term "psychosomatic” 
is widespread in the medical field, there are still some traditional biomedical currents that ignore the psychosomatic condition, considering only the biological factor as unique and determinant of human beings and their diseases (Haynal, Psini, \& Archinard, 2001).

The psychosomatic movement allowed the psychiatry entry into the general hospital, and with it, this was no longer an institution exclusively of doctors and nurses, starting to integrate in their teams and other professionals such as psychologists. As a result of this integration, numerous studies, as performed by Blachy and Starr, found that the presence of psychological disorders, for example, in the cardiac surgery preoperative, influenced the risk of mortality (Botega, 2002).

\section{Historical Aspects of Psychosomatic}

Since ancient times, the heart-mind relationship had been established through manifestation of emotions in the cardiovascular system. It is known that Hippocrates believed that mind and body were parts of an organism and that health would be a balance between these parts, and between them with the medium. In the Middle Ages, with the influence of the Church, there was a separation between mind and body, considering then illnesses as divine punishment (Romano, 2001).

Aristotle considered the body as an instrument of the soul, which uses it to act in the world and relate. Notwithstanding, to the philosopher the soul was a substance endowed with faculties, with specific and autonomic functions, which exists in a potential state, since there were bodily conditions for this (Junqueira Filho, 1995).

In the Renaissance, Descartes postulated the mind-body dualism, these parts being separated and different. For him, the body was thought to be a matter, a substance that occupies space and operates mechanically. The mind, for its part, was free and without any substance. Despite these differences, such parts were interrelated; thus, the mind wielded influence over the body, which could also influence it, and the point where this happened was in the pineal gland, or conarium (Junqueira Filho, 1995; Schultz \& Schultz, 2000).

To explain how this phenomenon used to occurr, Descartes suggested that a move produces an impression on the pineal gland and, from that, the mind generates a sensation. Regarding the influence that the mind exerts on the body, he explained that the mind leaves an impression on this gland, starting to influence nerves and muscles, resulting in movement. This position allowed greater centralization in the body, removing from the mind (soul) its sovereignty. With this, the functions previously assigned to mind, for example, locomotion and reproduction, now belong to the body. To the mind there was only one function: thinking (Schultz \& Schultz, 2000).

This vision of man composed of separate parts, concurrent with the development of pathological anatomy, microbiology and biochemistry, has allowed the creation of an organismic (biomedical) orientation of Medicine, in which diseases were seen exclusively as physical ailments, thus reducing the concern about the psychosocial aspects of the individual (Botega, 2002).

Contemporary of Descartes, Spinoza regarded the human body as a set of interconnected internal actions of organs, with dynamism, since the balance was obtained by continuous changes and by external relations, also continuous. In addition to it, the body was formed by affections, i.e., it possessed the ability to affect and be affected by other bodies, though without being destroyed. Spinoza denied that body, soul and man would be substances, but rather modifications and unique expressions of the activity of a single and infinite substance. Man was a unity of body and soul, both with equal forces. The soul was a force that was realized as imagination, desire and reflection (Junqueira Filho, 1995).

In the XX century, Freud, Cannon and Pavlov retake the psychological approach in the practice and in the medical research. By unravelling the unconscious sense of symptoms, or measuring the importance of emotions in the body functioning, it was observed the development of a psychological and neurophysiological model of man's unity (Botega, 2002).

It can be said that Freud marked a milestone in the relationship between psyche and soma through his interest in hysteria and the belief that the manifestations of this disease did not have any correspondence with the anatomical structure of the affected organs. By questioning the ways leading the psychic conflict to somatic manifestations, he founded the Psychoanalysis, seeking to understand the different passages and relations between the psychic and physical manifestations. From the investigation of the genesis of the conflict it can be understood the circumstances that culminate in the concretization of the human suffering on a psychic or somatic manifestation (Volich, 2000). It is in the conversion that is perceived the character of commitment with the symptoms, which express the repressed and repressive forces, as well as the dynamism between instinct and coun- 
ter-instinctive forces (Fenichel, 1998).

He explained that the surface of the psychic apparatus captures a stimulus, which is sent inside of this, activating the reactive impulses that were manifested on the surface. So it is up to the surface to capture and unload stimuli and the product of this differentiation becomes the ego. This, in turn, works both in reception and perception and in the authorization for the impulses to react. The ego also has an inhibiting function, which controls the body in the external environment and retains impulses which were not triggered, blocking, then, the unload (Fenichel, 1998).

The repressed contents seek motility, consciousness. There is an attempt to produce derivatives, shifting impulses for associative and connected ideas. In the psychoanalytic process, such contents are captured by the patient, knowing them gradually to the extent that the verbalization of which was suppressed is recovered. He also states that there are feelings, tensions in the individual, which, if not unloaded, will result in sensations, specific emotions called "unconscious desire for affection", contained by opposing forces (Fenichel, 1998).

Groddeck is considered the inventor of Id in psychoanalytic theory. This instance (referred to as "It") is expressed through symbols, and is defined as a force that mobilizes action, thought, growth, health, disease, finally, it is what makes life possible. For the Id, physiological changes correspond to a significant intentionality on the body scene, constituting a "mental imagery" of the affected organs and bodily functions. The somatic symptoms would express an economic value that assists in organizing the relationship between the outer and inner realities of an individual. The duration of these symptoms depends on the benefits provided by the Id, if revealed satisfactorily (Jeammet, Reynaud, \& Consoli, 2000)

Heinroth coined the term psychosomatic to refer to the influence of mind over body. The psychosomatic movement was born in Austria and Germany, and it has expanded in the US, with major theories about the relationship between the psychologic, the biologic and the social in determining health or disease. This was a reform movement against the reductionist view of the XIX century (Botega, 2002; Jeammet, Reynaud, \& Consoli, 2000).

The movement was only consolidated in the mid-twentieth century with Franz Alexander and the School of Chicago, who understood the personality as the expression of the unity of the body. Therefore, the body is understood from the standpoint of personality, whose needs are met by parts of the body (Mello Filho, 1992). It should be noted that it was important to differentiate the hysterical conversion reaction (in which there is no anatomical lesion) from the organic neurosis. The latter is characterized by being a physiological response to emotional states, which can be constant or periodic, with no intention of emotional discharges, and a possibility of generating organic injury. In the case of hysteria there is a symbolic expression of psychic contents, which attempt to discharge tensions, unlike the organic neurosis (Alexander, 2002).

The author believed that, for each emotional state, there would be a corresponding syndrome, as in physical changes and in psychosomatic responses, such as crying, laughing, changes in the cardiovascular system, etc. These are considered to have a passive nature, i.e., the symptom vanishes when the emotion disappears. He reported that some psychoanalysts tried to extend the concept of hysterical conversion, covering, then, all psychogenic disorders of the body. Thus, any physiological change had a symbolic meaning, hence disregarding the control exercised by the autonomic nervous system on the visceral organs. He explains that such organs can be influenced by emotional tensions (whether by inhibiting or by stimulating) (Alexander, 2002).

\section{Pierre Marty Ideas}

Another school that used the psychoanalytic theory as a basis (with emphasis on the economic aspects of the instinctual life) was the Psychosomatic School of Paris, led by writers such as Marty and M' Uzan, who founded it. The lower mental activity of an individual, the greater the somatic vulnerability, because the subject will not have enough resources to deal with the over-stimulation, which reaches the less evolved somatic functions. He understood the psychosomatic subject as having a poor fantasy life, with a hyposymbolization of affections, giving rise only to concrete contents. They are individuals superadapted to the world, which show a regression to a primitive level, with auto-agressive tendencies (Marty, 1993).

The French school sought to raise hypotheses that somatic patients had an incomplete building or atypical working on their mental apparatus. From these studies emerged concepts as "operational thinking” (1962), "essential depression" (1966) and "progressive disorganization” (1967). The operational thinking refers to a conscious thought, not linked to the representations, and that does not make use of neurotic or psychotic mechan- 
isms. In this kind of thinking there is no libidinal charge and the externalization of aggression is not always possible. This can be considered as secondary due to the sensible reality, the concern of causality, logic and continuity. There is also the precariousness of words connection, which Marty suggests as an archaic investment (Marty, 1993).

From these findings, Marty proposed a personality classification system, based on the psychosomatic balance of each individual, with three structural categories:

- "Well mentalized" neuroses: are individuals with certain limitation on the somatic vulnerability. They have good ability of psychic elaboration, with available fantasy life and a certain ease to mental representations.

- Neuroses "of sufficiently structured character": individuals who possess greater resistance to physical ailments, primarily using "character defenses" in the face of anguish. There is less ability to mental preparation of conflicts, with some stiffness, both in thoughts and in their relationships.

- Neuroses "of ill-structured character and of behavior": individuals with higher somatic vulnerability, showing great difficulties in mental elaboration of conflicts and with a low-permeable uncounscious functioning (Marty, 1993).

The operational thinking design has been replaced by a form of regressive psychic thought, in which there is an exacerbation of the most elaborated psychic defenses, with the fear for a somatic disorganization. In illstructured character and behavioral neuroses, it is noticed a greater predisposition to certain regressive movements in stressful situations. Such functioning may constitute the symptoms of essential depression, as it is sharply observed a decrease in the vital tone, an affective depletion of thought and the absence of sadness or moral pain. These characteristics allow a differentiation in relation to the clinical depression, which is classified as a mood disorder (Jeammet, Reynaud, \& Consoli, 2000).

Through his clinical experience, Dejours argues that both in psychoanalysis and in psychosomatics it is necessary to make a prediction, but aimed at a preparation for a surprise and with readiness to receive it. The author disagrees with Marty, among other aspects, when arguing that the somatic symptom has a meaning attached to the intersubjective dynamics. For him, this symptom is not a conversion nor resulting from repression (Dejours, 1998).

Fear of loss of relationships marked by dependence, may be an important factor for a psychophysiological disorder. Hence, a chronic resentment due to dissatisfaction of dependency needs is not explicitly expressed by the individual, because this runs the risk of losing the dependence which he cares most. In this sense, choleric reactions are suppressed, being therefore physically discharged. Denial is the main defense mechanism that works through the entire system of psychic events. This is because the patient cannot think psychologically, denying the existence of conflicts and resulting emotions, and their relationships with the symptoms (Mackinnon, Michels, \& Buckley, 2008).

The emotional reaction of each individual in the face of the disease depends on the following factors: personality structure, previous experiences with diseases, interpersonal relations, disease aggravating and hospitalization. In an attempt to adapt to the clinical situation, many regress emotionally; this can both awaken poorly designed emotional conflicts and provide ripening (PDM Task Force, 2006; Jeammet, Reynaud, \& Consoli, 2000).

\section{The Comes and Goes of Heart}

The heart is the depositary of numerous representations, and thus invested with a subjective meaning. The psyche can be considered as a sum of current and past experiences, felt and perceived in a unique way. Emotions can be considered as a class of phenomena felt internally, but signaled externally, whether by somatic or behavioral means. Emotions are acute emotional reactions triggered by external or internal stimuli, conscious or unconscious, and that often are accompanied by neurodegenerative, visceral, hormonal and vascular somatic reactions (Campos, 1992; Dalgalarrondo, 2000; Katon, Sullivan, \& Clarck, 1997).

Emotions are characterized by a sudden disruption of the affective balance. They are usually short episodes with concurrent or consecutive, mild or severe repercussions on several organs, creating a partial or total blockage of the ability to reason logically. This can cause a person to reach a high degree of psychic and behavioral decontrol. By contrast, feelings are seen as more durable affective states, causing less intensive experiences, with less impact on organ function and less interference with reason and behavior (Lent, 2001).

The heart is the most sensitive organ in the face of emotional repercussions due to its reaction to these. There are changes in beats, as tachycardias, and then a gap so that they return to normal. Nonetheless, when there is a 
constant return of these emotions, the heart becomes more sensitive and may undergo irreversible changes (Tamagnini, 2014).

The emotions-heart interaction has its defined biochemical correspondents, mediated by the sympathetic and parasympathetic systems, as well as hormones that integrate brain, heart and adrenal functions, for the heart is innervated by ramifications of the sympathetic and parasympathetic systems. When there is a stimulation of the sympathetic system, there is an increase in heart rate, contractile force and blood pressure. The stimulations of the parasympathetic modulate such responses directing them to the opposite direction (Campos, Navega, Ambrozim, Catai, \& Quitério, 2014; Straub, 2005)

The preference of a stressor agent for a particular organ, as well as the intensity of the response, depends on internal and external conditioning factors. The first are those that have been built according to the experiences and heredity. Environmental stress causes cardiovascular effects such as increased blood pressure, myocardial oxygen consumption, among others. These responses involve a physiological disorder, but the homeostatic return brings no lasting negative sequel. However, if an individual has a certain commitment, stress can cause several losses. The larger and more intense the action of stressors, the greater the impact on the cardiovascular system; and if there is still some constitutional flaw in this, there is greater vulnerability to stress (Campos et al., 2014; Oliveira, Sharovsky, \& Ismael, 2001; Ballone, 2015).

The accumulation of stressful life and the emotional changes-both positive in nature, such as job promotion, strong emotions etc., and of a negative order-are factors related to the development of coronary disease. It becomes important to trace the psychological profile of coronary patients, because, in this way, it is possible to identify individuals who, thanks to their profile, are more likely to develop coronary heart disease; in addition, the knowledge of the psychological profile will help clinical decision making (Campos, 1992; Oliveira, Sharovsky, \& Ismael, 2001; Ballone, 2015).

\section{Coronaropathy and Depression}

Coronaropathy is the most common disease of modern life and the leading cause of death worldwide, which often has a sudden onset, and, being chronic, causes the individual to live with it for life, despite having some periods of remission of symptoms. There are many factors that are considered as hazardous, as, for example, arterial hypertension, stress, sedentarism, hypercholesterolemia, hyperglycemia, among others. Although there is the contribution of constitutional factors in the origin of the disease, these are not always present, showing the involvement of environmental factors to its appearance. These have the capability of potentiating to each other, mainly depending on their intensities. Hence, the more frequent the presence of each factor, and the greater the enhancement by combination with other factors, the greater the influence on the disease (Cesar et al., 2014).

The coronary diseases can be divided into two groups. The first is the group of individuals who have organic predisposition. In this, the chance of illness occurs earlier, regarding the exposure to environmental factors. Therefore, illness or death of family members, marital conflict, job loss, personal or professional dissatisfaction, among others, may trigger coronary heart disease if there is an organic predisposition. The second group belongs to those individuals who do not have organic predisposition, but who are candidates for coronaropathy at older ages. In this, the lower the exposure to risk factors, the more advanced will be the age (Campos, 1992).

Every distress implies tension that can be reflected in the body area, generating, then, a somatic commitment, sometimes located in the cardiovascular system, often already impaired by coronary disease. Coronaropathy can be seen as an alternative to certain personality disorders, especially for those who culturally cannot help but be successful. Many people unconsciously "prefer" a heart attack to show their vulnerability and "weakness" through crying, passivity or dependence on others. In this way, sudden emotional shocks usually precede a heart attack (Ballone, 2015; Romano, 2008).

The term depression can mean a symptom that is part of many emotional disturbances without being exclusive of any of them. It may also be a syndrome translated by different somatic symptoms or, still, mean a disorder characterized by marked affective changes. As a symptom, depression can occur in response to stressful situations, or to adverse social and economic circumstances. As a syndrome, depression does not just include changes in mood (sadness, irritability, lack of ability to feel pleasure, apathy), but also a variety of other aspects such as cognitive, psychomotor and vegetative (sleep, appetite) changes (Del Porto, 2004).

According to DSM-5, the main feature of a Major Depressive Episode is a minimum period of two weeks, in which is noticed a depressed mood or loss of interest or pleasure in nearly all activities. There are also changes 
in appetite, sleep and psychomotor activity (both the agitation and the psychomotor retardation must be severe enough to be observable by others, not representing merely subjective feelings); decreased energy; feelings of worthlessness or guilt; difficulty to think, concentrate or make decisions. It is also observed the presence of recurrent thoughts of death or suicidal ideation. The episode must be accompanied by suffering or clinically significant impairment in social and occupational functioning or in other important areas of the individual's life. Some individuals report somatic complaints rather than feelings of sadness. Many report or exhibit increased irritability (APA, 2013).

Whenever there is discussion related to depression, it is necessary to consider psychodynamic, biological and neurophysiological factors. This is because psychosocial concerns such as: real or imagined loss, failure to meet the expectations of others and troubled relationships can trigger neurochemical and neurophysiological changes in the brain, which result in changes in the balance of neurotransmitters. In the psychodynamic understanding of depression, it should be considered premorbid personality factors, explaining that certain types or personality traits seem to predispose depression, as a stern, perfectionist superego can bring constant feelings of frustration due to heightened expectations in relation to themselves (Gabbard, 2015)

Depression is a risk factor for coronaropathy as important as smoking. It is associated with increased sympathetic activity in coronary patients, as the number of heartbeats is much higher in depressed patients with coronary artery disease, compared to non-depressed patients, regardless of age, gender, smoking option, etc. After the bypass surgery, the coronary artery disease patient presents some emotional disturbance and cognitive changes, which may be accompanied by other depressive symptoms and difficulty in psychosocial adjustment (Romano, 2008; Straub, 2005).

Chronic forms of depression can greatly affect each risk factor for coronaropathy, because the typical weight changes of the depressed have a negative effect on the disease, regardless of obesity and smoking, which is also increasingly associated with depression and other psychiatric disorders. The psychological stress recognized in it is a risk factor for coronary artery disease, regardless of age and other risk factors (Ballone, 2015; Romano, 2008; Straub, 2005; Maciel, 1994).

Coronaropathy emerges as an impediment to the continuity of life. It is also complemented that one of the main features in the coronary artery disease patient's personality is the concussion suffered by the loss of omnipotence and the feeling of having limitations. Anxiety emerges as both a physical (death), and a psychological threat (loss of freedom, meaninglessness). Despite varying from one individual to another, there is in all a common feeling, which is the threat of loss of life, of family, of socioeconomic status etc. Such feelings generate fear, anger and guilt. The patients may deny their disease, get angry, become aggressive, develop hypochondriacal complaints or, still, accept and cope with the disease (Ballone, 2015; Gabbard, 2015; Romano, 2008; Fráguas Júnior, 2002).

Many studies show that, independent of depression, anger is associated with increased cardiovascular risk. Anger in patients with low blood pressure and low risk for heart attack and coronary artery disease increased the risk of presenting cardiovascular disorder. The likelihood of a heart attack during an episode of anger is nine times higher than in any other time in life (Fráguas Júnior, 2002).

Arterial hypertension is also called "essential hypertension", in which the term "essential" is used to indicate an absence of an identifiable physical cause, the disorder being functional. Despite the etiological recognition, there is an obvious interaction between the psychosocial dimensions and the development of hypertension. There are relatively specific psychological profiles that have been assigned to patients suffering from hypertension: insecurity, constant sense of threat and ready defense, no expression of aggression (Maciel, 1994).

Usually they are sexually inhibited individuals, with conflicts between women's fashions or passive dependency and compensatory aggressive hostile impulses. Hostility breeds fear, leading to an attitude of passive dependence, which, in turn, causes feelings of inferiority and hostility, establishing thus a vicious circle. The antagonism aggression versus submission, at the same time stimulates and also does block, thus resulting in emotional paralysis (Alexander, 2002). Although agreeing with the reading of Alexander, Maciel highlights an aspect not mentioned by him and that has great influence, i.e., the sociocultural environment in which the individual is inserted. The conflict suppressed by the autonomic nervous system leads to an increased sympathetic or parasympathetic tone. This way, individuals with chronic conflict situations, in which the dependency is involved, are under constant stress, which, in turn, overstimulates the sympathetic system, resulting in a chronic state of alertness and consequently facilitating the onset of arterial hypertension (Alexander, 2002).

In Western culture the expression of anger is not well-accepted, requiring control over impulses. Some indi- 
viduals are more inhibited in regard to the expression of aggressive and self-assertive tendencies, not making use of suitable channels for its expression in a particular favorable situation, experiencing thus a chronically inhibited state of hostility (Ballone, 2015; Maciel, 1994).

\section{Final Considerations}

This work aimed to study the psyche-soma relationship and its implications for heart disease. With the technological development and the advancement of medicine, it has been allowed by doctors and patients to get ever earlier and accurate diagnoses, making the possibility of cure always high.

Psychology recognizes that the human being is constantly changing due to fluctuations in organic, environmental and psychosocial factors, and has emphasized, increasingly, its active role in the health-disease process.

In turn, the biomedical model, through its focus on pathogens, advanced the health care significantly. Notwithstanding, it was unable to explain certain diseases that had no observable physical cause, such as those discovered by Freud. Freud's patients revealed symptoms such as loss of speech, hearing and even paralysis, the etiology of which was not in the body, but rather caused by unconscious psychological conflicts.

Although Freud's psychoanalysis and the psychosomatic medicine were involved in a critical way, they formed the bases for further evaluation of the connections between medicine and psychology, ushering in the contemporary trend of seeing illness and health as something multifactorial, i.e., that many diseases were caused by the interaction of several factors, as is the case of heart diseases.

\section{References}

Alexander, F. (2002). Psychosomatic Medicine: Principles and Applications. Porto Alegre: Artes Médicas.

American Psychiatry Association (APA) (2013). Diagnostic and Statistical Manual of Mental Disorders 5. Washington: American Psychiatry Association.

Ballone, G. J. (2015). Relations between Emotions and Coronary Artery Disease, Myocardial Infarction, Hypertension and Arrhythmias. http://www.psiqweb.med.br/site/?area=NO/LerNoticia\&idNoticia=41

Bonomo, A. M. S., \& Araujo, C. C. F. (2009). Psychology Applied to Cardiology: A Study on Reported Emotions in Holter Examination. Psychology: Theory and Research, 25, 65-74.

Botega, N. J. (2002). Psychiatric Practice in the General Hospital: Interconsultation and Emergency. Porto Alegre: Artes Médicas.

Campos, E. P. (1992). Psychosomatic Aspects in Cardiology. In J. Mello Filho (Ed.), Psychosomatic Medicine Today (pp. 234-252). Porto Alegre: Artes Médicas.

de Campos, M. F., Navega, F. R. R., Ambrozim, A. B. P., Catai, A. M., \& Quitério, R. J. (2014). Autonomic Control of the Heart and Ejection in the Chronic Phase of Stroke. Brazilian Journal of Sports Medicine, 20, 438-441.

Cesar, L. A., Ferreira, J. F., Armaganijan, D., Gowdak, L. H., Mansur, A. P., Bodanese, L. C., Sposito, A., Sousa, A. C., Chaves, A. J., Markman, B., Caramelli, B., Vianna, C. B., Oliveira, C. C., Meneghetti, C., Albuquerque, D. C., Stefanini, E., Nagib, E, Pinto, I. M. F., Castro, I., Saad, J. A., Schneider, J. C., Tsutsui, J. M., Carneiro, J. K. R., Torres, K., Piegas, L. S., Dallan, L. A., Lisboa, L. A. F., Sampaio, M. F., Moretti, M. A., Lopes, N. H., Coelho, O. R., Lemos, P., Santos, R. D., Botelho, R., Staico, R., Meneghello, R., Montenegro, S. T., \& Vaz, V. D. (2014). Guidelines for Stable Coronary Artery Disease. Brazilian Society of Cardiology, 103, 1-14. http://www.arquivosonline.com.br/2015/

Dalgalarrondo, P. (2000). Psychopathology and Semiology of Mental Disorders. Porto Alegre: Artes Médicas.

Dejours, C. (1998). The Body between Biology and Psychoanalysis. Porto Alegre: Artes Médicas.

Del Porto, J. A. (2004). Concepts and Diagnoses. Brazilian Journal of Psychiatry, 21, 6-11.

Fenichel, O. (1998). Psychoanalytic Theory of Neurosis: Fundamentals and Basis of the Psychoanalytic Doctrine. São Paulo: Atheneu.

Fráguas Júnior, R. (2002). Dying Rage: Cardiovascular Effects of Hostility and Irritability. Being a Doctor Journal, São Paulo, 19. http://www.cremesp.org.br/?siteAcao=RevistaSerMedico

Gabbard, G. O. (2015). Psychodynamic Psychiatry in Clinical Practice. Porto Alegre: Artmed.

Haynal, A., Psini, W., \& Archinard, M. (2001). Psychosomatic Medicine: Psychosocial Approaches. Rio de Janeiro: Medsi. Ismael, S. M. C., \& Oliveira, M. F. P. (2001). Direction of Hospital Psychology in Cardiology. São Paulo: Papirus.

Jeammet, P., Reynaud, M., \& Consoli, S. (2000). Medical Psychology. Rio de Janeiro: Medsi. 
Junqueira Filho, C. U. (1995). Body and Mind: A Movable Frontier. São Paulo: Casa do Psicólogo.

Katon, W., Sullivan, M., \& Clarck, M. (1997). Psychological Factors Affecting the Medical Condition. In H. I. Kaplan, B. J. Sadock, \& J. A. Grebb (Eds.), Compendium of Psychiatry: Behavioral Sciences and Clinical Psychiatry (pp. 706-734). Porto Alegre: Artes Médicas.

Lent, R. (2001). One Hundred Billion Neurons: Fundamental Concepts of Neuroscience (pp. 651-680). São Paulo: Atheneu.

Maciel, C. L. C. (1994). Emotion, Disease and Culture: The Case of Essential Hypertension. In B. W. Romano (Ed.), Psychology Practice in Hospitals (pp. 2-32). São Paulo: Pioneira.

Mackinnon, R. A., Michels, R., \& Buckley, P. J. (2008). Psychiatric Interview in Daily Practice. Porto Alegre: Artes Médicas.

Marty, P. A. (1993). Psychosomatic Medicine in Adults. Porto Alegre: Artes Médicas.

Mello Filho, J. (1992). Psychosomatic Medicine Today. Porto Alegre: Artes Médicas.

Oliveira, M. F. P., Sharovsky, L. L., \& Ismael, S. M. C. (2001). Emotional Aspects of the Coronary Patient. In S. M. C. Ismael, \& M. F. P. Oliveira (Eds.), Direction of Hospital Psychology in Cardiology (pp. 185-198). São Paulo: Papirus.

PDM Task Force (2006). Psychodynamic Diagnostic Manual. Silver Spring, MD: Alliance of Psychoanalytic Organizations.

Romano, B. W. (2008). Clinical Psychology Manual for Hospitals. São Paulo: Casa do Psicólogo.

Romano, B. W. (2001). Psychology and Cardiology: Possible Encounters. São Paulo: Casa do Psicólogo.

Schultz, D. P., \& Schultz, S. E. (2000). History of Modern Psychology. São Paulo: Culrix.

Straub, R. (2005). Health Psychology. Porto Alegre: Artmed.

Tamagnini, E. J. G. (2014). Psychodynamics of the Patient with Heart Diseases: Contributions of Psychoanalysis to Cardiology. Doctoral Thesis, São Paulo: Institute of Psychology, USP.

Volich, R. M. (2000). From Hippocrates to Psychoanalysis. São Paulo: Casa do Psicólogo. 